\title{
Pregnancy Specific Beta-1 Glycoprotein in Women with Eclampsia, Kaduna State, Nigeria
}

\author{
Jim M. Banda ${ }^{*}$, Geoffrey C. Onyemelukwe², Bolanle O. P. Musa², Oladapo S. Shittu ${ }^{3}$, \\ Zulai A. Sarkin-Pawa ${ }^{3}$, Aliyu A. Babadoko ${ }^{4}$, Aisha I. Mamman", Adamu G. Bakari ${ }^{5}$, \\ Suraj Junaid 6 \\ ${ }^{1}$ Pathology Department, Faculty of Medicine, Kaduna State University, Kaduna, Nigeria \\ ${ }^{2}$ Immunology Unit, Department of Medicine, Ahmadu Bello University Teaching Hospital, Zaria, Nigeria \\ ${ }^{3}$ Department of Obstetrics and Gynaecology, Ahmadu Bello University Teaching Hospital, Zaria, Nigeria \\ ${ }^{4}$ Department of Haematology and Blood Transfusion, Ahmadu Bello University Teaching Hospital, Zaria, Nigeria \\ ${ }^{5}$ Department of Medicine, Ahmadu Bello University Teaching Hospital, Zaria, Nigeria \\ ${ }^{6}$ Federal College of Veternary and Medical Laboratory, National Veterinary and Research Institute, Vom, Nigeria \\ Email: "jimbanda31@yahoo.com
}

Received 2 November 2015; accepted 28 November 2015; published 3 December 2015

Copyright (C 2015 by authors and Scientific Research Publishing Inc.

This work is licensed under the Creative Commons Attribution International License (CC BY).

http://creativecommons.org/licenses/by/4.0/

(c) (1) Open Access

\section{Abstract}

This was a comparative cross-sectional study of eclamptic and normal healthy pregnant women conducted in kaduna State, Nigeria to determine Pregnancy Specific beta-1 Glycoprotein (PSG-1) levels in the peripheral blood of third trimester women with eclampsia $(E C ; n=38)$, normal healthy pregnant and non pregnant women controls (PC; $n=25$ and NPC; $n=25$ respectively), age and parity matched, attending labour rooms/wards and Antenatal Clinics (ANC) of Ahmadu Bello University Teaching Hospital Shika, Zaria and four other Hospitals in Kaduna state, Nigeria. Participants with smear positive malaria, seropositive for human immunodeficiency virus (HIV) or any other known clinical infection were excluded from this study. Pregnancy specific beta-1 glycoprotein levels were estimated using Quantikine ELISA kits. Data obtained were analyzed using SPSS version 20.0 (Chicago, USA) and Graph pad Prism 6.0. Results were expressed as mean \pm standard deviation while Kruskal Wallis test was used to determine the significant differences. A p-value of less than 0.05 was considered to be significant. The mean serum level of PSG-1 in EC was $2.53 \pm 0.11 \mathrm{pg} / \mathrm{ml}, \mathrm{PC} ; 2.56 \pm 0.03 \mathrm{pg} / \mathrm{ml})$ and NPC; $0.62 \pm 0.20 \mathrm{pg} / \mathrm{ml}$. There was no significant difference between EC and PC (P > 0.05). Pregnant women (with and without EC) had significantly higher mean serum values compared to NPC $p<0.05$. While pregnancy was associated with high levels of PSG-1, the study did not support the hypothesis of low PSG-1 level in EC. A longitudinal study to capture changes in PSG-I levels in the course of pregnancy as they manifest is recommended.

${ }^{*}$ Corresponding author.

How to cite this paper: Banda, J.M., Onyemelukwe, G.C., Musa, B.O.P., Shittu, O.S., Sarkin-Pawa, Z.A., Babadoko, A.A., Mamman, A.I., Bakari, A.G. and Junaid, S. (2015) Pregnancy Specific Beta-1 Glycoprotein in Women with Eclampsia, Kaduna State, Nigeria. Open Journal of Immunology, 5, 260-265. http://dx.doi.org/10.4236/oji.2015.55021 


\section{Keywords}

\section{Eclampsia, Pregnancy Specific Beta-1 Glycoprotein}

\section{Introduction}

Eclampsia has remained a significant public health threat in both developed and developing countries, contributing to maternal and perinatal morbidity and mortality globally [1] [2]. However, the impact of the disease is felt more severely in developing countries including Nigeria [3]-[5]. Report show that in Nigeria, 37,000 women die annually due to PE and EC related complications and it accounts for up to $40 \%$ of maternal death in Northern Nigeria [6].

Eclampsia, the occurrence of generalized convulsion (s) in association with signs of preeclampsia (hypertension and proteinuria) in pregnancy and not caused by epilepsy or other convulsive disorders in pregnancy. While pre-eclamppsia (PE) and EC are not distinct disorders but the manifestation of the clinical features of the same condition [7], some features suggest that EC may have an immune pathology [8]. Also susceptibility to EC varies from one woman to another, indicating genetic and immune factors [9].

Pregnancy-specific glycoproteins (PSGs) are expressed throughout human pregnancy and are the most abundant fetal proteins secreted by the placental syncytiotrophoblast into the maternal bloodstream in mid to late pregnancy ( 200 - $400 \mu \mathrm{g} / \mathrm{ml}$ ) [10]. Pregnancy specific glycoproteins are produced by ten PSG genes (PSG1PSG9, PSG11) and belong to the carcinoembryonic antigen (CEA) family, part of the immunoglobulin (Ig) super family [11].

Studies of PSG function have largely focussed on their role in modulating the maternal immune system. Pregnancy specific glycoproteins isolated from the human placenta have an inhibitory effect on phytohaemagglutinin or allogeneically stimulated lymphocytes [12]. Subsequently, it was shown that recombinant mouse and human PSGs induce production of anti-inflammatory cytokines such as interleukin-10 (IL-10) and transforming growth factor beta-1 (TGF $\beta 1$ ) by monocytic, macrophage and dendritic lineages in vitro and in vivo [13] [14]. In the human, elevated PSG levels are associated with improved symptoms of rheumatoid arthritis during pregnancy [15]. These findings are consistent with PSGs contributing to modulation of maternal immune responses during pregnancy. More recently, PSGs were shown to be pro-angiogenic in in vitro assays, an activity mediated by interactions with cell surface glycosaminoglycans and the induction of TGF $\beta 1$ and vascular endothelial growth factor A (VEGF-A) [16]. Pregnancy specific glycoproteins are expressed from the preimplantation blastocyst stage of development [17] and therefore may have a role in promoting angiogenesis in the placental bed in the early pregnancy, or perhaps in vascular endothelial protection and repair in the maternal circulation in later pregnancy. Consistent with the proposed immunoregulatory and angiogenic functions of PSGs, deregulation of PSG expression has been reported in disorders of pregnancy associated with pro-inflammatory and anti-angiogenic phenotypes. For example, low levels of PSGs have been reported in maternal circulation of first and second trimester pregnancies complicated by intrauterine growth retardation and preeclampsia [18], [19]. What are the alterations or changes that may occur in PSG-1 levels women with established EC? This question therefore, forms the basis of this study. The objective of this study was to measure PSG-1 levels in the peripheral blood of women with EC and to compare the data obtained with values in normal pregnant women and normal healthy non-pregnant controls with the hope of understanding the role of PSG-1 in the pathogenesis of EC.

\section{Materials and Methods}

\subsection{Study Area}

This was a comparative cross sectional study, conducted in Gynaecology and Obstetrics Departments of Ahmadu Bello University Teaching Hospital (ABUTH) Shika, Zaria, Hajiya Gambo Sawaba General Hospital (HGSGH), Zaria, Barau Dikko Specialist Hospital (BDSH) Kaduna, Yusufu Dantsoho Memorial Hospital (YDMH) Kaduna and General Hospital (GH) Kafanchan. Patients and controls were enrolled as they present. Ethical clearance was obtained from the Scientific and Health Research Ethics Committee of the Ahmadu Bello University teaching hospital Shika-Zaria and the Kaduna State Ministry of Health (KSMOH) before commencing the study. Patients retained the right to deny consent for or opt out of the study at any stage. Patient confi- 
dentiality was maintained throughout the study.

For the women with EC: third trimester women with identifying features of high blood pressure $(\geq 140 / 90)$, proteinuria (2+ dip stick testing of random urine) and tonic-clinic convulsion, who were previously normotensive and nonproteinuric after 20 weeks of gestation [20]. For the controls: third trimester healthy pregnant women (normotensive and nonproteinuric) age and parity matched with EC above and non-pregnant healthy (normotensive and nonproteinuric) age matched with EC and PC [21]. Participants that refused consent or opt out, tested sero-positive for human immunodeficiency virus (HIV), blood smear positive for malaria test, or any known clinical disorder were excluded from the study.

\subsection{Clinical Evaluation and Selection of Participants}

All the participants were briefed about the nature of the study and written informed consent was taken from all the recruits. Blood pressure was measured using a simple mercury sphygmomanometer on right hand arm in a supine position after $10 \mathrm{~min}$. rest by the collaborating clinician at the antenatal clinic (ANC)s of the Obstetrics and Gynaecology Department of the respective hospitals. To perform dipstick urine analysis, combi-2 Medi-test strips were used. Clients who fulfilled the entry criteria were enrolled for the study. Participant's personal data such as age and parity, etc. were sourced from each participant in addition to the data resulting from the clinical and laboratory examination and entered into the study.

\subsection{Blood Sample Collection.}

A total of $5 \mathrm{mls}$ of blood were drawn from each research participants, after confirmation of diagnosis and before the administration of any drugs into plain tubes. Serum were extracted and stored in pre-labelled serum vials containing drops of trasylol (aprotonin)-Sigma USA and stored at $-20^{\circ} \mathrm{C}$ to inhibit degradation of PSGs.

\subsection{PSG-1 Assay}

Pregnancy specific beta-1 glycoprotein was assayed on batched serum samples by quantikine ELISA kits following the outlined protocol by pathare et al. [22]. Frozen $\left(-20^{\circ} \mathrm{C}\right)$ serum samples were thawed once and brought to room temperature at the time of assay. Serum samples (EC; $n=38$, PC; $n=25, N P C ; n=25$ ) were dispensed along side with dilutions of standards (recombinant PSG-1) into wells of the micro titre ELISA plates pre-coated with monoclonal antibodies against the human PSG-1 to be assayed and incubated at room temperature for 2 hours. The plates were washed four times with buffer (phosphate buffer saline- $0.05 \%$ and Tween 20). Conjugates (polyclonal antibody against PSG-1 to horseradish peroxidase-HRP) were added and incubated for 2 hours at room temperature. Unbound enzymes were washed out while the bound enzymes were then detected by incubation in the dark with substrate solutions (stabilized hydrogen peroxides and tetramethylbenzidine-TMB). The plates were scanned using a microplate reader (Bio-Rad, USA) set at $450 \mathrm{~nm}$ with wave length correction set at $570 \mathrm{~nm}$. A standard curve was then generated from the known standards. Concentrations of PSG-1 in the specimen were determined by comparing sample optical density with the values on the standard curve.

\subsection{Statistical Analysis}

The data obtained were analysed using the SPSS version 20.0 (Chicago, USA) and Graph Pad Prism 6.0. Results were expressed as mean \pm standard deviation. Kruskal Wallis was used to determine significant differences. Comparisons were made between EC, PC and NPC. Test was carried out at 0.05 level of significant and $p<0.05$ was considered significant.

\section{Results}

\subsection{The Demographic and Clinical Characteristics of Women with EC, PC and NPC}

The mean age and standard deviation of the groups were similar: EC ( $25.0 \pm 5.9$ years), PC (24.9 \pm 5.7 years) and NPC (25.1 \pm 5.9 years). The mean gestational age and parity for patients and controls were also similar: EC (37.2 \pm 2.2 weeks and $1.4 \pm 2.4)$ and PC; (37.1 \pm 2.0 weeks and $1.5 \pm 2.5)$ respectively. Similarly, the mean BMI and standard deviation recorded was: EC $\left(26.4 \pm 4.3 \mathrm{Kg} / \mathrm{m}^{2)}\right.$, PC $\left(25.8 \pm 3.7 \mathrm{Kg} / \mathrm{m}^{2)}\right.$ and NPC $\left(25.2 \pm 4.3 \mathrm{Kg} / \mathrm{m}^{2}\right)$. There was no statistical difference between EC, PC and NPC $(P>0.5)$ (Table 1$)$. However, the mean values of 
blood pressures (systolic; diastolic) and standard deviation were noted to be higher in EC (171.6 $\pm 25.2 \mathrm{mmHg}$; $110.0 \pm 10.7 \mathrm{mmHg})$ compared with PC, $(111.6 \pm 7.1 \mathrm{mmHg} ; 79.5 \pm 11.3 \mathrm{mmHg})$ and NPC, $(109.6 \pm 6.6$ mmHg; $84.2 \pm 6.4 \mathrm{mmHg})$. There were significant differences between EC, PC and NPC $(p<0.05)$ (Table 1$)$. Most of the eclamptic women (55.3\%) were not booked in the facility at the time of study. While $100 \%$ of the pregnant women control had been booked who served as controls (Table 1). Urinary proteins (albumin), $\geq 2+$ were recorded in all eclamptic women and non in PC and NPC. Similarly, tonic-clonic convulsions that occurred antepartum (16; 42.1\%) and intrapatum (22; 57.9\%) were recorded in the eclamptic women and non in the pregnant and non pregnant controls (Table 1 ).

Table 1. The demographic and clinical characteristics of women with EC, PC and NPC (Mean and \pm SD).

\begin{tabular}{|c|c|c|c|}
\hline Characteristics & $\mathrm{EC}(\mathrm{n}=38)$ & $\mathrm{PC}(\mathrm{n}=38)$ & NPC $(n=38)$ \\
\hline Age (years) & $25.0 \pm 5.9$ & $24.9 \pm 5.7$ & $25.1 \pm 5.9$ \\
\hline Gestational age (wks) & $37.2 \pm 2.2$ & $37.1 \pm 2.0$ & - \\
\hline BMI $\left(\mathrm{Kg} / \mathrm{m}^{2}\right)$ & $26.4 \pm 4.3$ & $25.8 \pm 3.7$ & $25.2 \pm 4.3$ \\
\hline Systolic BP (mmHg) & $171.6 \pm 25.2^{*}$ & $111.6 \pm 7.1$ & $109.6 \pm 6.6$ \\
\hline $\begin{array}{c}\text { Diastolic BP (mmHg) } \\
\text { Proteinuria }\end{array}$ & $\begin{array}{c}110.0 \pm 10.7^{*} \\
\geq 2+\end{array}$ & $\begin{array}{l}79.5 \pm 11.3 \\
\text { Not detected }\end{array}$ & $\begin{array}{c}84.2 \pm 6.4 \\
\text { Not detected }\end{array}$ \\
\hline Antenatal booking & $55.3 \%$ & $100.0 \%$ & - \\
\hline Antepartum convulsion & 16 (42.1\%) & - & - \\
\hline Intrapartum convulsion & $22(57.9 \%)$ & - & - \\
\hline
\end{tabular}

EC = Eclampsia, $\mathrm{PC}=$ Healthy Pregnant Control, NPC = Healthy Non Pregnant Control, BMI=Body Mass Index, BP= Blood Pressure * Eclampsia is significantly different from both controls at $p<0.05$.

\subsection{Pregnancy Specific Beta-1 Glycoprotein Levels in Eclampsia, Pregnant and Non-Pregnant Controls}

In Table 2, the mean serum (log value) of PSG-1 in EC was $2.53 \pm 0.11 \mathrm{pg} / \mathrm{ml}$, while for the PC and NPC; it was $2.56 \pm 0.03 \mathrm{pg} / \mathrm{ml}$ and $0.62 \pm 0.20 \mathrm{pg} / \mathrm{ml}$ respectively.

While there was no significant difference between EC and PC $(P>0.05)$, women with EC had significantly higher mean serum values compared to NPC $p<0.05$.

Table 2. Pregnancy specific beta-1 glycoprotein levels in eclampsia pregnant and non-pregnant controls.

\begin{tabular}{ccccc}
\hline Parameter & EC $(\mathrm{n}=38)($ mean $\pm \mathrm{SD})$ & PC $(\mathrm{n}=25)($ mean $\pm \mathrm{SD})$ & NPC $(\mathrm{n}=25)($ mean \pm SD $)$ & P-value \\
\hline Log PSG-1 $(\mathrm{pg} / \mathrm{mL})$ & $2.53 \pm 0.11$ & $2.56 \pm 0.03$ & $0.62 \pm 0.20$ & \\
Kruskal-Wallis & 56.46 & 57.82 & 13.00 & $<0.001^{*}$ \\
\hline
\end{tabular}

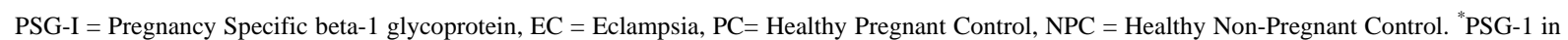
EC and PC are significantly different from NPC $P<0.05$.

\section{Discussion.}

\section{Pregnancy Specific Beta-1 Glycoprotein (PSG-1)}

The result of this study showed that women with EC and normal healthy pregnant women had higher mean serum levels of PSG-1 $(P<0.05)$ compared to concentration recorded in healthy non pregnant controls. Although, there was a decrease in the mean serum PSG-1 levels among the eclamptic women compared to the normal healthy pregnant group, the difference was not significant $(P>0.05)$.

This result agrees with findings of Onyemelukwe et al. [23] who studied 71 normal healthy pregnant women in northern Nigeria. They documented a low rise in PSG-1 up to 24 weeks, then a steep rise up to 36 wks followed by a gradual fall near term. The result of this study whoever, did not support the findings of Silver et al. [24] who reported significant low PSG levels in PE, the precursor of EC.

Pregnancy specific beta-1 glycoprotein, the major placental glycoproteins are a group of highly similar proteins synthesized in large amounts by the placenta trophoblast that together with the carcinoembryonic antigens 
comprise a subfamily within the immunoglobulin (Ig) super family [25]. During normal pregnancy, PSG molecules are released into the maternal circulation reaching $200-400 \mu \mathrm{g} / \mathrm{ml}$ in the serum at the end of gestation [26] and are thought to play a crucial role in supporting gestation and foetus protection against the maternal immune system [27]. Sacks et al. [28] proposed that pregnancy-specific factors induce the suppression of a specific arm of the maternal response and assumes the central role in maternal immunological adaptation. PSG modulates the immune response by inducing the secretion of anti-inflammatory cytokines such as IL-10, IL- 6 and TGF- $\beta$ by human and murine cells ([29] [30]). PSG also suppress mixed lymphocyte reaction and T cell activation by mitogens [12].

In this study, the slight decreased mean PSG-1 value in the eclamptic women compared to normal healthy pregnant women control might in part be associated with the pathogenesis of EC. Lower levels of PSG-1 have been associated with certain human, pathological conditions such as autoimmune disease, spontaneous abortion, fetal retardation, low birth weight and hypoxia [27] [31]-[33].

Sacks et al. [28] have proposed that soluble placental products released directly into maternal circulation can generate specific pregnancy signals through interaction with innate immune system. Thus the innate immunity might be able to distinguish pregnant from non-pregnant states, producing unique signals that promote or prevent the lymphocytes response to alloantigen stimulation. While pregnancy is generally associated with high levels of PSG-1, the study did not support the hypothesis of low PSG-1 level in EC. There is a need for a longitudinal study to capture changes in PSG-1 levels as they occur for better understanding of pathophysiology of eclampsia as it surfaces.

\section{References}

[1] Ghulmiyyah, L. and Sibai, B. (2012) Maternal Mortality from Preeclampsia and Eclampsia. Seminars in Perinatology, 36, 56-59. http://dx.doi.org/10.1053/j.semperi.2011.09.011

[2] WHO (2011) Recommendations for Prevention and Treatment of Preeclampsia and Eclampsia. WHO Department of Maternal and Child Health, Geneva.

[3] Acquaah-Arhin, R. and Kwakwukume, E.Y. (2003) Trends in Eclampsia in Ghana at Korle-Bu Teaching Hospital, Accra, Ghana. Nigerian Journal of Clinical Practice, 6, 1-4

[4] Adamu, Y.M., Salihu, H.M., Sathiakumar, N. and Alexander, G.R. (2003) Maternal Mortality in Northern Nigeria: A Population-Based Study. European Journal of Obstetrics Gynecology and Reproductive Biology, 109, 153-159. http://dx.doi.org/10.1016/S0301-2115(03)00009-5

[5] Igberase, G. and Ebeigbe, P. (2006) Eclampsia: Ten-Years of Experience in a Rural Tertiary Hospital in the Niger Delta, Nigeria. Journal of Obstetrics and Gynaecology, 26, 414-417. http://dx.doi.org/10.1080/01443610600720113

[6] WHO (2004) Coverage of Maternity Care: A Listing of Available Information. World Health Organization, Geneva.

[7] Shah, A.K. (2009) Preeclampsia/Eclampsia. http://emedicine.medscape.com/article/118427\%200-overview

[8] Saito, S., Nakashima, A., Sakai M. and Sakai, Y. (2007) The Role of Immune System in Preeclampsia. Molecular Aspect of Medicine, 28, 192-209. http://dx.doi.org/10.1016/j.mam.2007.02.006

[9] Duley, L. (2009) The Global Impact of Preeclampsia and Eclampisa. Seminars in Perinatology, 33, 130-137. http://dx.doi.org/10.1053/j.semperi.2009.02.010

[10] Zhou, G.Q., Baranov, V., Zimmermann, W., Grunert, F., Erhard, B., et al. (1997) Highly Specific Monoclonal Antibody Demonstrates That Pregnancy-Specific Glycoprotein (PSG) Is Limited to Syncytiotrophoblast in Human Early and Term Placenta. Placenta, 18, 491-501. http://dx.doi.org/10.1016/0143-4004(77)90002-9

[11] Kammerer, R. and Zimmermann, W. (2010) Coevolution of Activating and Inhibitory Receptors within Mammalian Carcinoembryonic Antigen Families. BMC Biology, 8, 12. http://dx.doi.org/10.1186/1741-7007-8-12

[12] Harris, S.J., Anthony, F.W., Jones, D.B. and Masson, G.M. (1984) Pregnancy-Specific Beta 1-Glycoprotein: Effect on Lymphocyte Proliferation in Vitro. Journal of Reproductive Immunology, 6, 267-270. http://dx.doi.org/10.1016/0165-0378(84)90015-9

[13] Ha, C.T., Waterhouse, R., Warren, J., Zimmermann, W. and Dveksler, G.S. (2005) N-Glycosylation Is Required for Binding of Murine Pregnancy-Specific Glycoproteins 17 and 19 to the Receptor CD9. American Journal of Reproductive Immunology, 59, 251-258. http://dx.doi.org/10.1111/j.1600-0897.2007.00573.x

[14] Martínez, F.F., Knubel, C.P., Sánchez, M.C., Cervi, L. and Motrán, C.C. (2012) Pregnancy-Specific Glycoprotein 1a Activates Dendritic Cells to Provide Signals for Th17-, Th2-, and Treg-Cell Polarization. European Journal of Immunology, 42, 1573-1584. http://dx.doi.org/10.1002/eji.201142140

[15] Fialova, L., Kohoutova, B., Pelísková, Z., Malbohan, I. and Mikulíková, L. (1991) Serum Levels of Trophoblast-Specific 
Beta-1-Globulin (SP1) and Alpha-1-Fetoprotein (AFP) in Pregnant Women with Rheumatoid Arthritis. Ceská Gynekologie, 56, 166-170.

[16] Ha, C.T., Wu, J.A., Irmak, S., Lisboa, F.A. and Dizon, A.M.L. (2010) Human Pregnancy Specific Beta-1-Glycoprotein 1 (PSG1) Has a Potential Role in Placental Vascular Morphogenesis. Biology of Reproduction, 83, 27-35. http://dx.doi.org/10.1095/biolreprod.109.082412

[17] Jurisicova, A., Antenos, M., Kapasi, K., Meriano, J. and Casper, R.F. (1999) Variability in the Expression of Trophectodermal Markers Beta-Human Chorionic Gonadotrophin, Human Leukocyte Antigen-G and Pregnancy Specific Beta-1 Glycoprotein by the Human Blastocyst. Human Reproduction, 14, 1852-1858. http://dx.doi.org/10.1093/humrep/14.7.1852

[18] Bersinger, N.A. and Odegard, R.A. (2004) Second and Third-Trimester Serum Levels of Placental Proteins in Preeclampsia and Small-for-Gestational Age Pregnancies. Acta Obstetrics and Gynecology of Scandavania, 83, 37-45. http://dx.doi.org/10.1111/j.1600-0412.2004.00277.x

[19] Pihl, K., Larsen, T., Laursen, I., Krebs, L. and Christiansen, M. (2009) First Trimester Maternal Serum PregnancySpecific Beta-1-Glycoprotein (SP1) as a Marker of Adverse Pregnancy Outcome. Prenatal Diagnosis, 29, 1256-1261. http://dx.doi.org/10.1002/pd.2408

[20] Chesley, L.C. (1985) Diagnosis of Preeclampsia. Obstetrics and Gynecology, 65, 423-425.

[21] Teran, E., Escudero, C., Moya, W., Flores, M., Vallance, P. and Lopez-Jaramillo, P. (2001) Elevated C-Reactive Protein and Pro-Inflammatory Cytokines in Andean Women with Preeclampsia. International Journal of Obstetrics and Gynecology, 75, 243-249. http://dx.doi.org/10.1016/S0020-7292(01)00499-4

[22] Pathare, A., Al Kindi, S., Alnaqdy, A., Daar, S., Knox-Macauly, H. and Dennison, D. (2004) Cytokine Profile of Sickle Cell Disease in Oman. American Journal of Hematology, 77, 323-328. http://dx.doi.org/10.1002/ajh.20196

[23] Onyemelukwe, G.C., Ekwempu, C.C. and Alexander, L.C. (1985) Pregnancy Specific Glycoprotein (PSG1) in Normal Pregnancy in Nigeria. Internal Journal of Obstetrics and Gynaecology, 23, 347-349. http://dx.doi.org/10.1016/0020-7292(85)90032-3

[24] Silver, R.M., Heyborne, K.D. and Leslie, K.K. (1993) Pregnancy Specific Beta 1 Glycoprotein (SP-1) in Maternal Serum and Ammiotic Fluid; Pre-Eclampsia, Small for Gestational Age Fetus and Fetal Distress. Placenta, 14, 583-589. http://dx.doi.org/10.1016/S0143-4004(05)80211-5

[25] Horne, C.H., Towler, C.M., Pugh-Humphreys, R.G., Thomson, A.W. and Bohn, H. (1976) Pregnancy Specific Beta-1Glycoprotein: A Product of the Syncytiotrophoblast. Experientia, 32, 1197-1199. http://dx.doi.org/10.1007/BF01927624

[26] Lin, T.M., Halbert, S.P. and Kiefer, D. (1976) Quantitative Analysis of Pregnancy-Associated Plasma Proteins in Human Placenta. Journal of Clinical Investigations, 57, 466-472. http://dx.doi.org/10.1172/JCI108298

[27] Lisboa, F.A., Warren, J., Sulkowski, G., Aparicio, M., David, G., et al. (2011) Pregnancy-Specific Glycoprotein 1 Induces Endothelial Tubulogenesis through Interaction with Cell Surface Proteoglycans. Journal of Biological Chemistry, 286, 7577-7586. http://dx.doi.org/10.1074/jbc.M110.161810

[28] Sacks, G., Sargent, I. and Redman, C. (1999) An Innate View of Human Pregnancy. Immunology Today, 20, $114-118$. http://dx.doi.org/10.1016/S0167-5699(98)01393-0

[29] Snyder, S.K., Wessner, D.H. Wessells, J.L., Waterhouse, R.M., Zimmermann, W. and Dveksler, G.S. (2001) Pregnancy-Specific-Beta1 Glycoprotein Function as Immunomodulators by Inducing Secretion of IL-10, IL6 and TGF by Human Monocytes. American Journal of Immunology, 45, 205-216. http://dx.doi.org/10.1111/j.8755-8920.2001.450403.x

[30] Blois, S.M., Sulkowski, M., Tirado-Gonzalez, I., Warren, J., Freitag, N., Klabb, B.F., Rifkin, D., Fuss, I., Strober, W. and Dveksler, G.S. (2014) Pregnancy Specific Beta-1 Activates Transformation Growth Factor Beta-1 and Prevent Dextran Sodium Sulfate-Induced Colitis in Mice. Mucosal Immunology, 7, 348-358. http://dx.doi.org/10.1038/mi.2013.53

[31] Masson, G.M., Anthony, F. and Wilson, M. (1983) Value of Schwangerschftsprotein 1 (SP1) and Pregnancy-Associated Plasma Protein A (PAPP-A) in the Clinical Management of Threatened Abortion. British Journal of Obstetrics and Gynaecology, 90, 146-149. http://dx.doi.org/10.1111/j.1471-0528.1983.tb08899.x

[32] Tamsen, L., Johansson, S.G. and Axelsson, O. (1983) Pregnancy-Specific Beta 1-Glycoprotein (SP1) in Serum from Women with Pregnancies Complicated by Intrauterine Growth Retardation. Journal of Perinatal Medicine, 11, 19-25. http://dx.doi.org/10.1515/jpme.1983.11.1.19

[33] Arnold, L.L., Doherty, T.M., Flor, A.W., Simon, J.A., Chou, J.Y., Chan, W.Y. and Mansfield, B.C. (1999) PregnancySpecific Glycoprotein Gene Expression in Recurrent Aborters: A Potential Correlation to Interleukin-10 Expression. American Journal of Reproductive Immunology, 41, 174-182. http://dx.doi.org/10.1111/j.1600-0897.1999.tb00530.x 